\begin{tabular}{|c|c|c|c|c|c|}
\hline MUNIBE Antropologia-Arkeologia & $n^{\circ} 72$ & $171-184$ & DONOSTIA & 2021 & ISSN 1132-2217 • eISSN 2172-4555 \\
\hline
\end{tabular}

\title{
Estudio del edificio romano junto al lavajo El Monduengo. Nuevos datos del complejo de la villa romana de Almenara de Adaja-Puras, Valladolid
}

\author{
Study of the Roman building at El Monduengo lagoon. \\ New data for the villa complex of Almenara de Adaja-Puras, Valladolid
}

PALABRAS CLAVES: Arqueología romana, villa romana, valle del Duero, teledetección, fotografía aérea, prospección geofísica, georradar GAKO-HITZAK: Erromatar arkeologia, erromatar hiribildua, Duero harana, teledetekzioa, aireko argazkia, prospekzio geofisikoa, georradarra. KEY WORDS: Roman villa, Ground Penetrating Radar, aerial photography, remote sensing, Duero valley.

Jesús GARCÍA SÁNCHEZ(1), Margarita SÁNCHEZ-SIMÓN(2)

\section{RESUMEN}

Las fotografías aéreas realizadas por Julio del Olmo en 1999 nos han permitido conocer de primera mano la existencia de un edificio de probable cronología romana junto al lavajo El Monduengo (Puras, Valladolid). Esta zona se localiza inmediatamente al sur de la villa romana de La Calzadilla, también conocida como villa romana de Almenara de Adaja-Puras, que se encuentra al sur de la provincia de Valladolid. Se ubica en una zona muy cercana a Coca (Segovia), la Cauca prerromana y romana cuya influencia seguramente se hizo sentir en el ritmo de colonización del campo de época romana altoimperial.

En este trabajo proponemos la revisión de una de esas imágenes aéreas oblicuas tomadas por Julio del Olmo ya que, a pesar de su perspectiva, consta de gran calidad y además es la única que hasta 2020 nos mostraba los restos soterrados de este edificio.

Además, hemos explorado las posibilidades para la teledetección que nos brinda la amplia serie de ortofotografías disponibles para la zona, incluyendo series históricas como USAF Serie B y el Vuelo Interministerial. Para la realización de este estudio, hemos empleado los fotogramas infrarrojos junto a la tradicional ortofotografía PNOA tomada en el espectro visible RGB, para calcular una serie de índices de vegetación y suelo que usan principalmente las bandas Roja e Infrarroja. Este trabajo de teledetección se ha realizado únicamente con imágenes públicas y software open-source (QGIS, R Project, SNAP).

El estudio de la documentación gráfica nos ha llevado a plantear una prospección geofísica mediante georradar (Noggin 250 MhZ) para obtener una imagen actual y precisa que nos permita conocer la extensión y morfología de dicho edificio. Los datos obtenidos nos permiten comprender la evolución del yacimiento de Almenara de Adaja-Puras a lo largo de la época romana tardía con posterioridad al siglo III d.C. Además, comparamos esta estructura con algunas otras similares conocidas tanto en el propio yacimiento de La Calzadilla, como en otros del valle del Duero.

\section{LABURPENA}

Julio del Olmok 1999an airetik egin zituen argazkiei esker lehen gertu-gertutik ahal izan dugu El Monduejo (Puras, Valladolid) putzuaren alboan ustez erromatar garaikoa den eraikin bat dagoela. Eremu hori La Calzadilla erromatar hiribilduaren hegoaldean dago, Almenara de Adaja-Puras erromatar hiribildua izenarekin ere ezagutzen dute eta Valladolid probintziaren hegoaldean dago. Cocatik (Segovia) oso hurbil dago, garai aurre-erromatarrean eta erromatarrean Cauca zena, eta ziurrenik eragin nabarmena izan zuen Erromako goi-inperioaren garaian landa-eremuko lurrak kolonizatzeko erritmoan.

Lan honetan, Julio del Olmoren aireko irudi zeihar horietako bat berrikustea proposatu dugu. Izan ere, perspektiba gorabehera, kalitate handia du eta, gainera, 2020ra arte eraikin horren lurperatutako zatiak erakusten zituen bakarra da.

Bestalde, eskuragarri dauden eremu hartako ortoargazkien sorta zabalak eskaintzen dizkigun teledetekziorako aukerak aztertu ditugu, sorta historikoak barne, hala nola USAF B Sorta eta Ministerio arteko Hegaldia. Ikerketa hau egiteko, fotograma infragorriak eta RGB espektro ikusgaian ateratako PNOA ortoargazki tradizionala erabili ditugu, banda Gorriek eta Infragorriek gehien erabiltzen duten landareen eta lurzoruaren adierazle-sorta kalkulatzeko. Teledetekziorako lan hau irudi publikoekin eta open-source softwareekin (QGIS, R Project, SNAP) soilik egin dugu.

Dokumentazio grafikoaren ikerketak eraman gaitu georradarrarekin (Noggin $250 \mathrm{MhZ}$ ) azterketa geofisikoa egitea planteatzera, egungo irudi zehatz bat lortzeko eta eraikin horren hedadura eta morfologia hobetu ezagutu ahal izateko. Lortutako datuei esker hobeto uler dezakegu Almenara de Adaja-Puras aztarnategiak erromatar garai berantiarrean, K.o. III. mendearen ondoren, izan zuela bilakaera. Gainera, egitura hori antzeko beste batzuekin alderatu dugu, bai La Calzadilla aztarnategi bertakoekin bai Duero haranekoekin.

\footnotetext{
(1) Instituto de Arqueología, Mérida. CSIC-Junta de Extremadura. Plaza de España 15, 06800 Mérida, Badajoz. E-mail: j.garcia@iam.csic.es. (2) Universidad de Burgos. Facultad de Humanidades y Comunicación, Paseo de Comendadores s/n (Hospital Militar) 09001 Burgos. E-mail: massimon@ubu.es.
} 


\section{ABSTRACT}

In 1999, the aerial photographs taken by Julio del Olmo of several archaeological sites in the Duero valley allowed us to discover the existence of a new Roman building in the area of El Monduengo lagoon. This area is located immediately south of the well-known Roman villa of La Calzadilla, also known as the villa of Almenara de Adaja-Puras, in the south of the province of Valladolid, very close to Coca, the pre-Roman and Roman city of Cauca, whose influence was felt in the pace of Roman expansionism in countryside during the Early Imperial period.

In this paper we propose to revisit of one of these oblique aerial images taken by Julio del Olmo, which, despite its oblique perspective, is of great quality. Moreover, even today, it is also the only image to date that shows us the buried remains of this Roman building.

In addition, we have explored the possibilities for remote sensing provided by the wide range of publicly available orthophotographs, including historical series such as USAF Series B and the Interministerial Flight. In order to carry out this remote sensing study, we have used the Near Infrared frames recorded alongside the traditional PNOA orthophotography in the visible RGB spectrum. Using both RG and NIR bands we calculate vegetation and soil indices; these indices employ chiefly the Red and Near Infraed band of the electromagnetic spectrum. This remote sensing work has been carried out only with public images and open-source software (QGIS, R Project, SNAP).

The study of the graphic documentation has led us to carry out a geophysical survey using Ground Penetrating Radar (Noggin 250 mhz). This way we obtain an updated and accurate image of the extension and morphological characteristics of the new building. This work is carried out in order to improve our understanding of the evolution of the Almenara de Adaja-Puras site from the end of the Late Iron Age to the Late Roman period. In addition, we compare this building with some other structures of a similar type known both at the La Calzadilla site and in other sectors of the Duero Valley.

\section{INTRODUCCIÓN}

En 1999, Julio del Olmo fotografió desde el aire el área del lavajo El Monduengo (Puras, Valladolid), revelando la existencia de un edificio de aproximadamente $2.000 \mathrm{~m}^{2}$ en las inmediaciones de la villa tardorromana de La Calzadilla (también llamada villa romana de Almenara de Adaja-Puras), conocida desde finales del siglo XIX y objeto de un importante proyecto de investigación desde 1996 (García-Merino \& Sánchez-Simón,
2015, 2017) (Figuras 1 y 2). Las fotografías oblicuas de Del Olmo muestran un conjunto de estancias organizadas en un plano consistente y regular (Del Olmo, 2017, pp. 69-71; García Merino \& Sánchez Simón, 2015, pp. 69-70). Sin embargo, el autor comprende que dicha fotografía no presenta las estructuras de una manera totalmente clara. A nuestro juicio, la falta de contraste cromático entre las marcas en el cultivo y su entorno inmediato quizás se deba a la fecha temprana en la que se tomó la imagen, no estando el ciclo fenológico

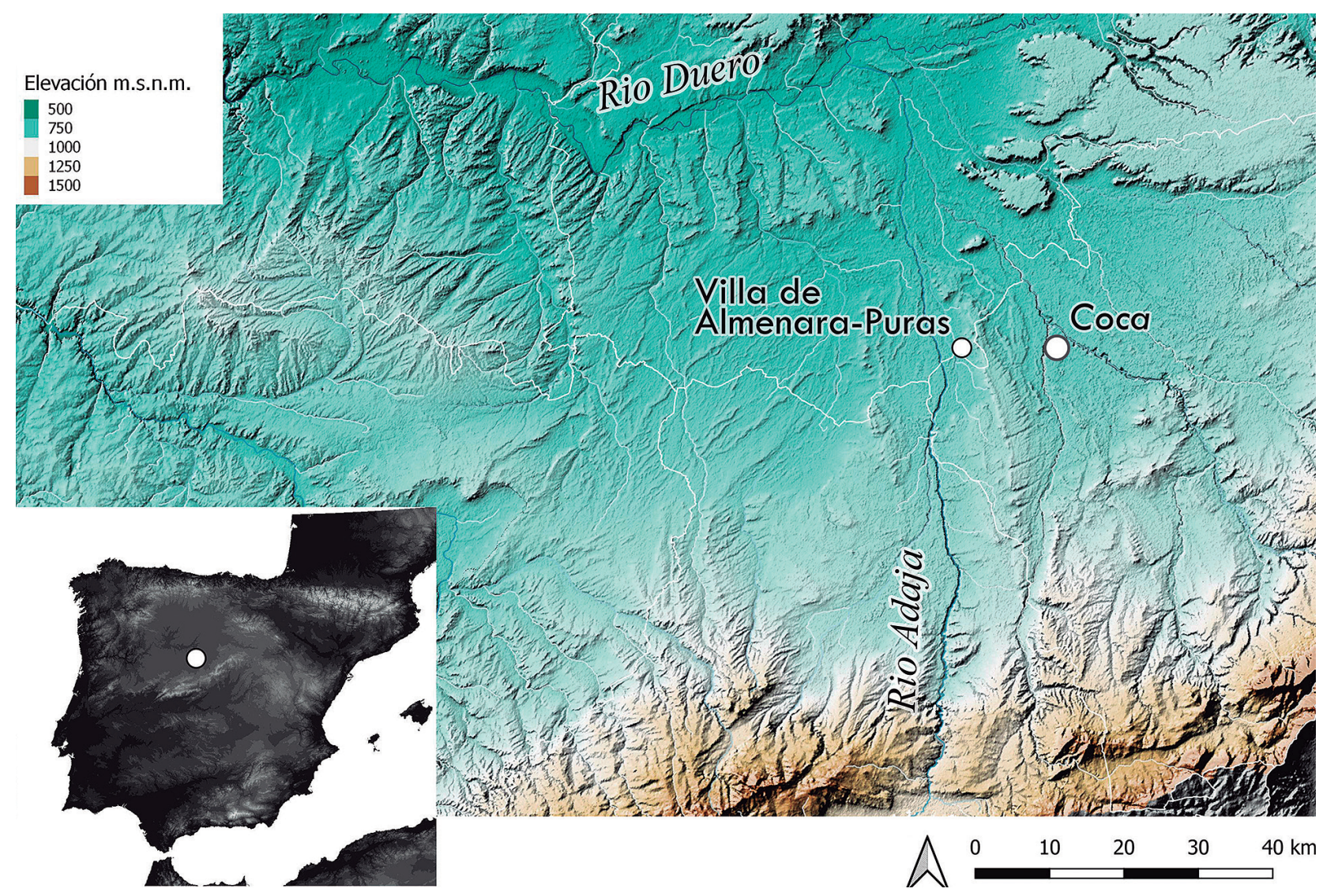

Fig. 1. Localización de villa de Almenara de Adaja y Cauca en la cuenca del río Duero. Elaboración propia. / Location of the Roman villa of Almenara-Puras and the city of Cauca in the Duero valley basin. Image by authors. 
del cultivo aún completo. No obstante, la perspectiva oblicua permite reconocer el crecimiento diferencial del cultivo gracias a la proyección de las sombras de las estructuras que conforman este edificio.

Además de esta imagen, Del Olmo tomó varias fotografías que permiten reconocer las dos alas rústicas de la villa tardía, otra más aparentemente aislada al noroeste del palacio y un pequeño edificio exento (Del Olmo, 2017, pp. 69-70, 2017, fig. 23-24).

En el marco de las investigaciones sobre el yacimiento, este edificio (conocido únicamente por prospecciones aéreas) se asocia con una fase anterior a la de la villa tardía (construida a mediados del siglo IV d.C.), a un momento entre el siglo III y primera mitad del IV d.C. En este momento, en torno al lavajo de El Arroyuelo se estaba desarrollando una intensa actividad antrópica materializada, principalmente, en la construcción de una serie de edificios alargados del tipo de alas rústicas, de unas pequeñas termas y en la formación de un potente vertedero en los márgenes de ese bodón (García-Merino \& Sánchez-Simón, 2015, pp. 69-72). La prospección terrestre en las parcelas donde se sitúa esa compleja edificación, realizada en 1997 por el equipo del Inventario Arqueológico de la Provincia de Valladolid (Universidad de Valladolid), no aportó datos concluyentes que permitan afinar su cronología, hallándose en este sector del yacimiento materiales de época alto y bajoimperial.

En el presente trabajo nos centramos en los restos de ese complejo ubicado junto al lavajo de El Monduengo (Figura 2, núm. 4). Para su estudio se han empleado únicamente métodos no invasivos sobre dos parcelas situadas junto a la villa de Almenara de Adaja-Puras, para comprender mejor el complejo desarrollo del sistema vilicario en el valle del Duero (García Entero 2007). Los siguientes apartados desarrollan y presentan la metodología de trabajo que parte del estudio de las fotografías de Julio del Olmo, investiga las series históricas y actuales de ortofotografía aérea mediante técnicas de teledetección y, finalmente, desarrolla las conclusiones de una prospección geofísica mediante georradar.

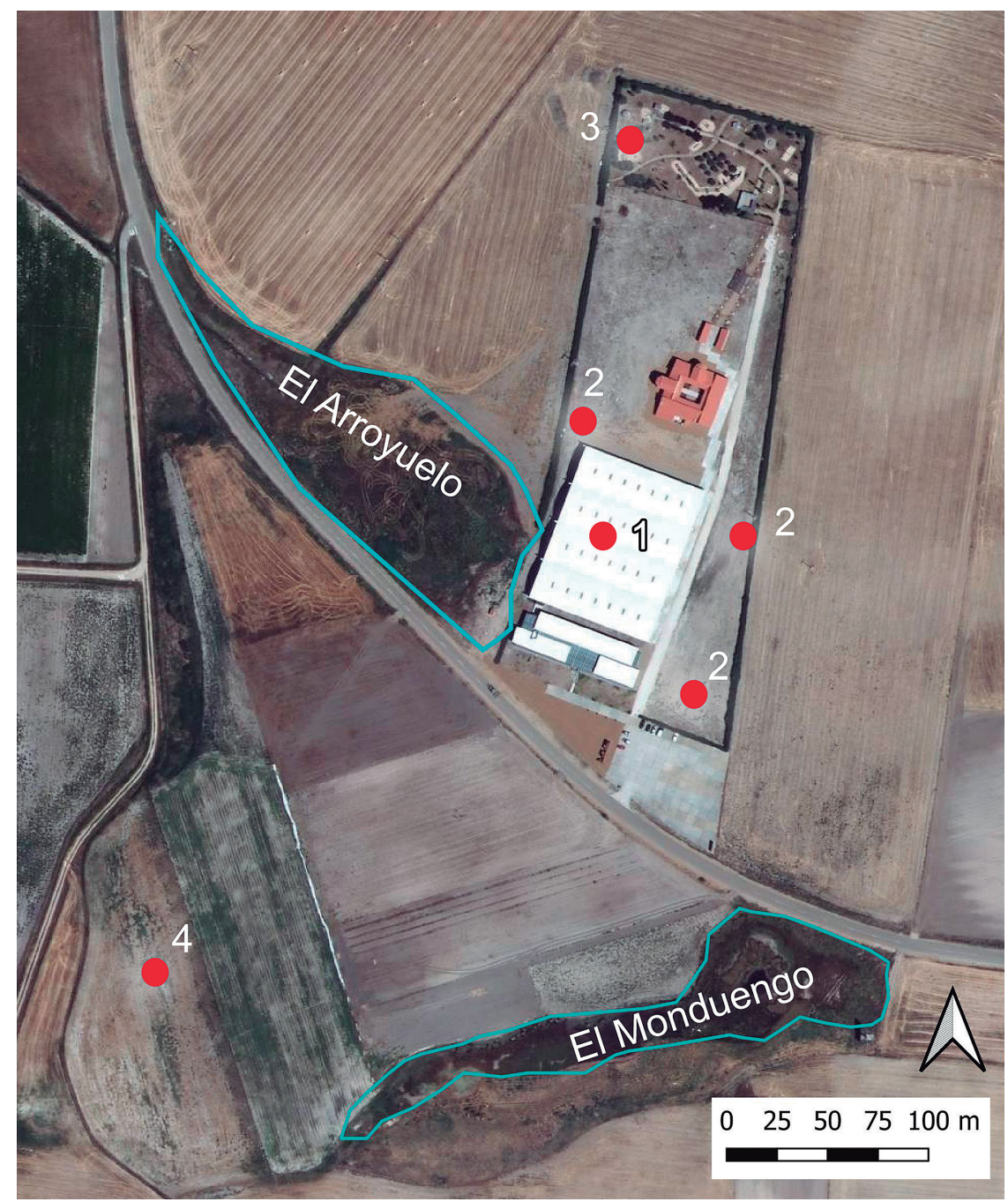

Fig. 2. Ortofoto PNOA 2014 del área ocupada por el yacimiento arqueológico. 1.- Residencia bajoimperial e instalaciones rústicas del siglo III-primera mitad del IV; 2.- Alas rústicas tardías; 3.- Área ocupada por el hábitat altoimperial y la necrópolis tardorromana; 4.- Edificio romano conocido por ortofotos y georradar. Elaboración propia a partir de García-Merino y Sánchez-Simón, 2015, p. 66, fig. 37. / Ortophoto PNOA 2014 of the area occupied by the archaeological complex of Almenara-Puras 1.Late Roman villae and and rural features from 3rd-first half of 4th century AD. 2.-Rural areas of the Late Roman villae. 3.-Early Empire Roman villa, and Late Roman necropolis. 4.-Building discovered by orthophoto and GPR. Image by authors after García-Merino y Sánchez-Simón, 2015, p. 66, fig. 37. 


\section{METODOLOGÍA}

Partiendo de la fotografía oblicua de Del Olmo (2006, 2017), que evidencia la presencia de un edificio junto al lavajo de El Monduengo, se ha desarrollado un trabajo basado en dos métodos de estudio no destructivos, teledetección y prospección geofísicas. Se ha planteado una revisión de la fotografía aérea disponible y una prospección geofísica mediante georradar. El empleo de métodos de prospección no destructivos es una línea de trabajo consolidada a nivel internacional y en especial en el arco mediterráneo. Los ciclos agrarios y las capacidades pedológicas de los suelos permiten la detección remota de estructuras arqueológicas mediante fotografía aérea (Campana \& Piro, 2008; Mayoral Herrera, 2016; Opitz \& Cowley, 2013; Palmer \& Cowley, 2010; Vermeulen, 2013). En la literatura arqueológica del valle del Duero abundan los ejemplos de la aplicabilidad de la fotografía aérea (Ariño et al., 2004; Brassous et al., 2015; Didierjean, 2015; García Sánchez, 2012; Garcia Sanchez \& Costa García, 2020; Liz Guiral
\& Célis Sánchez, 2007). Por su parte, la prospección mediante georradar es uno de los métodos geofísicos más populares para la documentación tridimensional de estructuras soterradas en medios poco conductivos; su aplicación a gran escala ha permitido además la documentación precisa de diferentes tipos de evidencias arqueológicas de época romana, desde edificios rurales aislados a conjuntos urbanos completos (Conyers, 2004; Verdonck et al., 2012, 2020).

Durante el año 2020 se han tomado también algunas fotografías aéreas mediante UAVs con el fin de comparar la imagen de Julio del Olmo. Desgraciadamente, el estado de los cultivos no ha permitido documentar ninguna de las estructuras conocidas previamente. Estos resultados se han debido a dos causas; en primer lugar al estado del cultivo en el momento del vuelo UAV (mayo y junio de 2020) y a la alta humedad en la zona producida por abundantes lluvias durante el ciclo del cereal; en segundo lugar, la parcela en la que su ubica gran parte del edificio se encuentra en barbecho para la plantación de girasol.
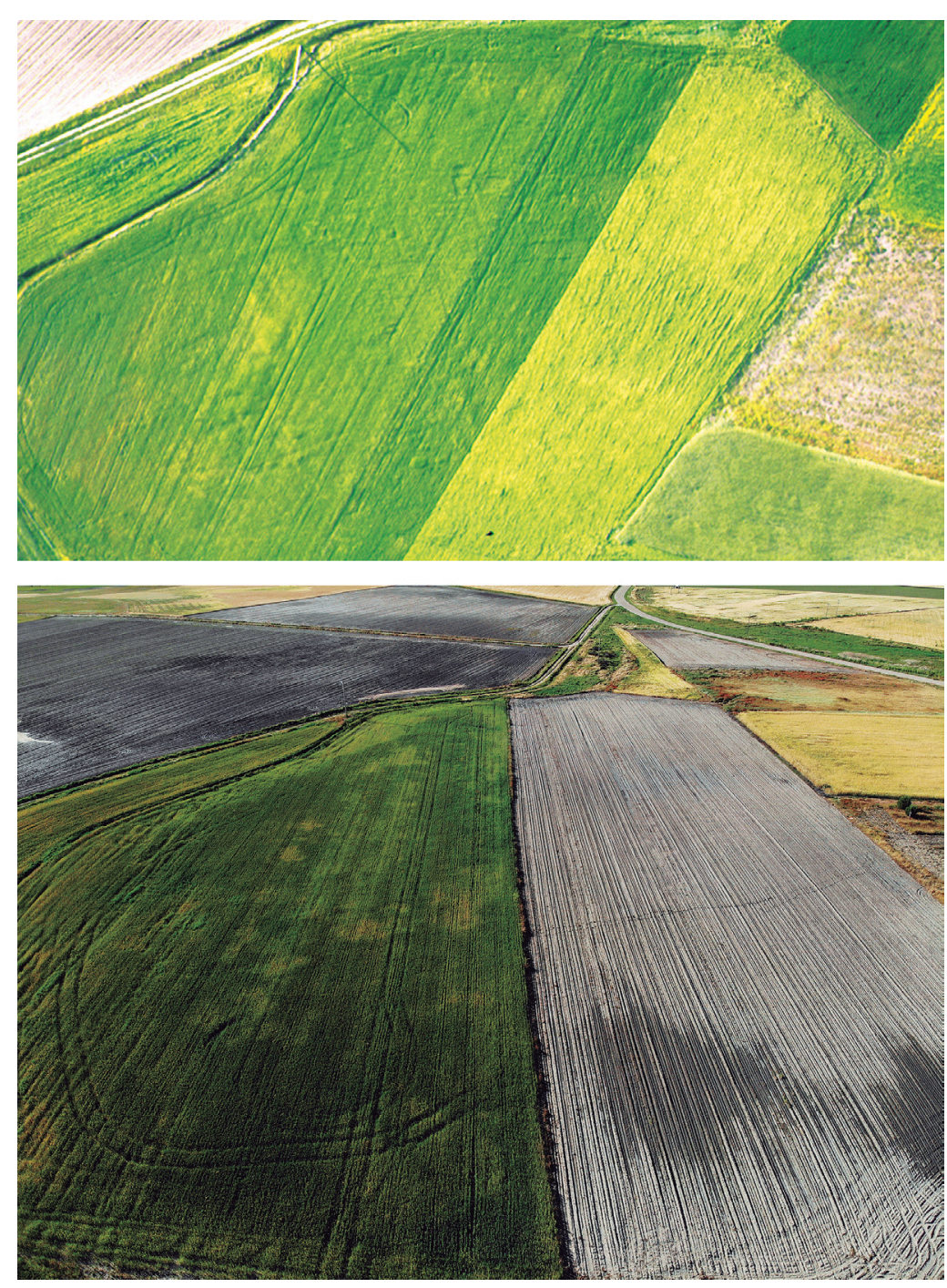

Fig. 3. Arriba. Fotografía oblicua de Julio del Olmo (2017, fig. 25), fecha original del vuelo: 1999. Abajo, fotografía oblicua ( 5 de junio de 2020). / Oblique image from Julio del Olmo (2017, fig. 25), flight from 1999 (Above). Oblique image by authors (5 $5^{\text {th }}$ June 2020) (Below). 


\subsection{Fotografía aérea}

La primera aproximación al área del lavajo de El Monduengo ha consistido en la revisión de las series de fotografías aéreas disponibles para esta zona. Se han analizado los fotogramas de la serie PNOA accesibles a través de la IDEE de Castilla y León desde el año 2000 hasta la actualidad, y las fotografías históricas de la serie B de la USAF, conocida como vuelo americano de 1956, y la documentación fotográfica del IRYDA tomada entre 1973 y 1988. Estos dos productos históricos nos muestran la organización de la propiedad antes de la concentración parcelaria y los diferentes tipos de cultivos que nos permiten contrastar las imágenes más modernas y descartar "falsos amigos" en la interpretación de trazas de posibles estructuras soterradas.

Además de las imágenes generadas por las instituciones públicas y disponibles a través de las IDEE regional y nacional, se han revisado las satelitales accesibles a través de las plataformas de Google Earth, Yahoo Bing, y Google Maps siguiendo la metodología recientemente propuesta por Menéndez Blanco et al. (Menéndez Blanco et al., 2020) para el reconocimiento de marcas en el cultivo (cropmarks) en el valle del Duero.

Más allá del uso de imágenes RGB (Red, Green, Blue) que muestran el rango visible del espectro electromagnético, se ha empleado también la banda del Infrarrojo cercano de las imágenes para mejorar la detección de trazas arqueológicas en las zonas de cultivo o en los campos con vegetación de tipo arbustivo o forraje (también llamados yeros en la zona). El empleo de imágenes infrarrojas (Verhoeven, 2012a, 2012b) cuenta con amplio predicamento en proyectos de teledetección puesto que permite la creación de índices específicos para el análisis y clasificación de los cultivos y su relación con elementos arqueológicos (Salgado Carmona et al., 2020); y también para incrementar la visualización de determinados elementos arqueológicos. En el caso del valle del Duero los recintos de fosos calcolíticos ofrecen uno de los mejores ejemplos de aplicación (García García, 2013).

Se ha seleccionado un fotograma PNOA en RGB y NIR de 2010 donde varias parcelas del entorno de la villa de Almenara de Adaja-Puras presentan vegetación (cultivos o vegetación arbustiva) en superficie. Esta imagen no es óptima para nuestro objetivo puesto que los cultivos muestran un estrés escaso como para permitir la detección de elementos arqueológicos.

El cálculo de varios índices de los cultivos se ha realizado en $\mathrm{R}$ con base en el script multispectral desarrollado por Bonn Center for Digital Humanities ${ }^{1}$ que emplea a su vez el script RStoolbox de B. Leutner². El script multispectral nos permite calcular una amplia gama de índices y su exportación como geotiff para su integración en un SIG junto con los datos del proyecto que, en este caso, son las imágenes RGB provenientes de las series fotográficas históricas de los vuelos PNOA y las imágenes de satélite ya mencionadas, además de los datos de las prospecciones geofísicas desarrolladas por nosotros en el sitio y que desglosamos en el siguiente apartado.

En este caso se han elegido 6 índices de vegetación de forma exploratoria: NDVI (Normalized Difference Vegetation Index), DVI (Difference Vegetation Index), GNDVI (Green Normalized Difference Vegetation Index), WDVI (Weighted Difference Vegetation Index), GEMI (Global Environmental Monitoring Index) y SAVI (Soil Adjusted Vegetation Index). Además de los índices de vegetación se han calculado en el programa SNAP, de la Agencia Espacial Europea, cuatro índices de suelo: $\mathrm{BI}$ (Brightness Index), Bl2 (Second Brightness Index), Cl (Color Index) y RI (Redness Index) cuyo empleo en teledetección aplicada a la arqueología está bien atestiguado (Bennett et al., 2012; Donati \& Sarris, 2016; Salgado Carmona et al., 2020; Uribe Agudo et al., 2018).

Los índices de vegetación que se muestran como mosaico empleando una paleta de colores graduada similar (spectral) como ouput del script multispectral se exportan a geotiff para poder ser estudiados de forma individual en QGIS utilizando paletas de color similar y calculando las estadísticas según el lienzo actualizado, un método similar al propuesto por García García (2013) para ArcGIS.

Los índices de suelo se han calculado empleado la herramienta SNAP de la Agencia Espacial Europa ${ }^{3}$ de forma similar a la elaborada por Salgado $(2020,3)$.

\subsection{Prospección geofísica - Georradar}

De cara a documentar los restos del edificio y a evaluar su estado de conservación se planteó una prospección geofísica empleando el método del Ground Penetrating Radar o georradar. Este método permite obtener una imagen del subsuelo en forma de radargramas que muestran la refracción de un pulso electromagnético (EM) al encontrar los límites entre materiales con diferentes constantes dieléctricas (Goodman \& Piro 2013). Parte de este pulso EM se transmitirá a través del material gracias a su valor de permitividad dieléctrica y parte se disipará en función de la conductividad eléctrica del subsuelo. Los radargramas muestran perfiles individuales registrados por un transecto del sistema de georradar y pueden posteriormente interpolarse para la creación de imágenes a diferentes profundidades dada una velocidad de propagación de las ondas EM en el subsuelo (Catapano et al., 2019; Conyers, 2004).

\footnotetext{
1 https://github.com/bcdhbonn/multispectral

2 https://github.com/bleutner/RStoolbox

3 https://github.com/senbox-org/
} 

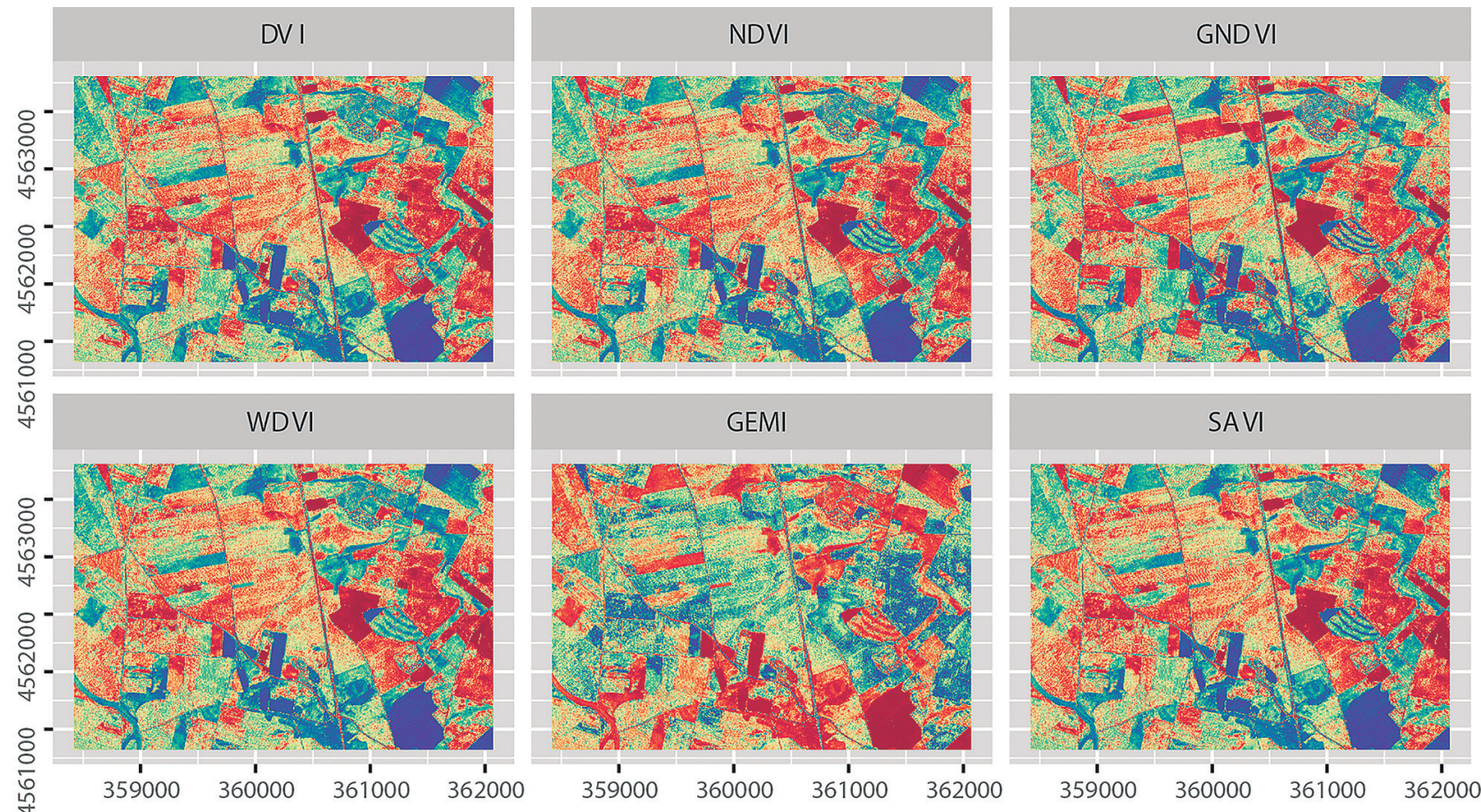

Fig. 4. Mosaico con índices de vegetación calculados el script multispectral para la hoja PNOA 428/5-7 de 2010. Combinación RGB+infrarrojo. Elaboración propia. / Vegetation indexes mosaic created using multispectral script for a RGB-NIR combination of image PNOA 428/5-7 2020. Image by authors.

En esta ocasión se ha empleado un sistema Noggin $250 \mathrm{MHz}$ de Sensor and Software montado sobre un Smart Car. La prospección se ha efectuado empleando cuadrículas de diverso tamaño adaptadas al terreno y fusionadas más adelante en Ekko Project. Los cuadros han sido prospectados mediante transectos separados $50 \mathrm{~cm}$ y orientados en el eje $Y$ respecto al punto de origen de cada cuadro. Este sistema se ha demostrado exitoso en prospecciones similares (Manataki et al., 2015; Sarris et al., 2020; Sarris \& Cantoro, 2015). La resolución, aunque menor que en las prospecciones desarrolladas con equipos de multisensores (Manataki et al., 2015; Seren et al., 2007) sí permite la documentación de las estructuras conservadas en el subsuelo a una profundidad considerable (Seren et al., 2007).

\begin{tabular}{|l|l|}
\hline \multicolumn{1}{|c|}{ Categoría } & \multicolumn{1}{c|}{ Noggin 8250 MHz } \\
\hline Tamaño & $63 \times 41$ X 23 CM \\
\hline Peso & $7.3 \mathrm{KG}(12.5 \mathrm{LBS})$ \\
\hline Centro de la Frencuencia & $250 \mathrm{MHZ}$ \\
\hline -6dB Bandwidth & $125-375 \mathrm{MHZ}$ \\
\hline Shielding Front to Back & $>20 \mathrm{DB}$ \\
\hline Ventana de tiempo máximo* & $2,000 \mathrm{NS} @ 0.4 \mathrm{NS} / \mathrm{PT}$ \\
\hline Profundidad máxima & $100 \mathrm{M}(328 \mathrm{FT})$ \\
\hline
\end{tabular}

Tabla 1: Características técnicas del sistema Noggin $250 \mathrm{MHz}$ de Sensors and Software empleado en la prospección de El lavajo de El Monduengo. / Technical description of the GPR system (Noggin $250 \mathrm{mhz}$ ) used in the survey of El Monduengo.
El proceso de los datos se ha realizado en Ekko Project siguiendo el método propuesto por Manataki et al. ( 2015, pp. 19-20) para el mismo sistema Noggin, en el que se busca mejorar el procesamiento estándar ofrecido por el software. Este proceso se compone de los siguientes pasos:

\section{Corrección del momento 0.}

2. Dewow.

3. Compensación de atenuación mediante el método SEC (Spreading \& Exponential Compensation).

4. Background substraction filter.

5. Band pass filter.

6. Migración de los datos conforme al método de estimación de hipérbola.

Finalmente, los cortes de datos efectuados cada 10 $\mathrm{cm}$ se han georreferenciado para su digitalización y tratamiento en QGIS junto al resto de información del proyecto.

\section{RESULTADOS}

Exponemos a continuación los resultados de las dos líneas de trabajo efectuadas en nuestra investigación. En primer lugar, trataremos del análisis de la fotografía de Julio del Olmo y de las otras series de imágenes, desde las USAF serie B del 1956 hasta las más recientes del PNOA en RGB-NIR que nos permiten el cálculo de diversos índices para maximizar la información de la zona. En segundo lugar, desarrollaremos los resultados de la prospección geofísica. 


\subsection{Resultados del análisis de las imágenes aéreas}

La georreferenciación de la foto oblicua de Del Olmo nos permite reconocer las estancias que componen este edificio documentado junto a El Monduengo. A pesar de la obvia distorsión de la imagen, podemos reconocer un espacio a cielo abierto (1) en cuyo lado noroeste se disponen dos ámbitos (2). Al oeste, el otro posible patio (4) cuenta con trazas en su entorno que parecen estar haciendo referencia a diferentes espacios de índole indeterminada.

Aunque el resultado final adolece de gran distorsión y las mediciones efectuadas sobre ella tienen poca fiabilidad, la imagen nos permitirá contrastar el resultado de la prospección geofísica.

El análisis de las series fotográficas históricas nos permite reconocer algunos elementos más. La cobertura de 1956 muestra el momento anterior a la concentración parcelaria, con una división de la propiedad muy atomizada. En ella se intuyen dos alineamientos formando una $L$ invertida coincidente con la orientación general del edificio, en la zona ocupada por la estructura antes referida como 3 (Figura 5, derecha, estructura señalada por una flecha).

La fotografía del vuelo Interministerial (1977-1983) revela una decoloración en el área central del conjunto. Esta zona se estructura siguiendo el patrón regular de la villa, según lo observado en la fotografía de del Olmo; además las estructuras 7 y 6 parecen observarse adecuadamente (Figura 5, centro)

La serie del PNOA resulta poco productiva a la hora de evaluar estas parcelas. Uno de los principales problemas es la escasa resolución temporal (registradas por PNOA cada dos años) de las imágenes y el hecho de que el momento en el que se tomaron no era el adecuado para registrar cambios en el ciclo fenológico del cultivo. Además, podemos observar rotaciones en el uso del suelo en esta zona que dificultan aún más la tarea de recrear la planimetría del sitio.

En la imagen de Apple Maps $^{4}$ (ver Figura 6) se intuye de nuevo una línea transversal al parcelario moderno, con ligera decoloración del cultivo (clorosis).

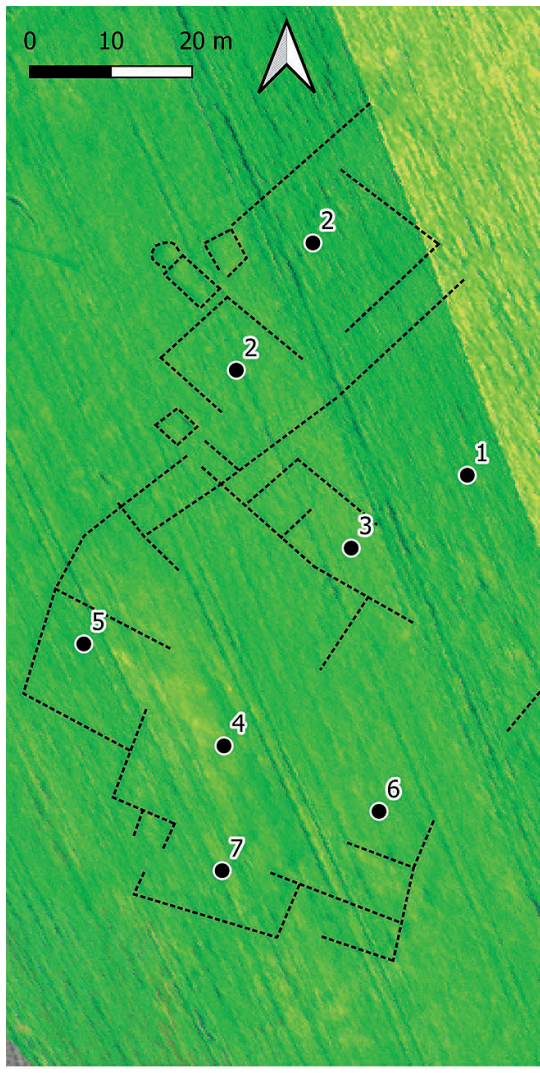

Fotografía oblícua rectificada de J. del Olmo

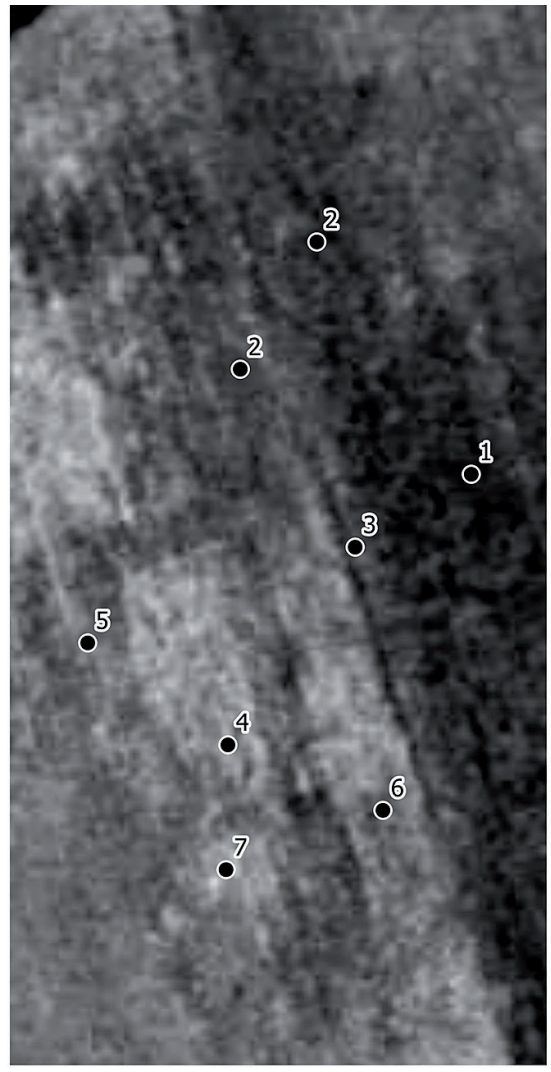

Vuelo Interministerial 1977-1983

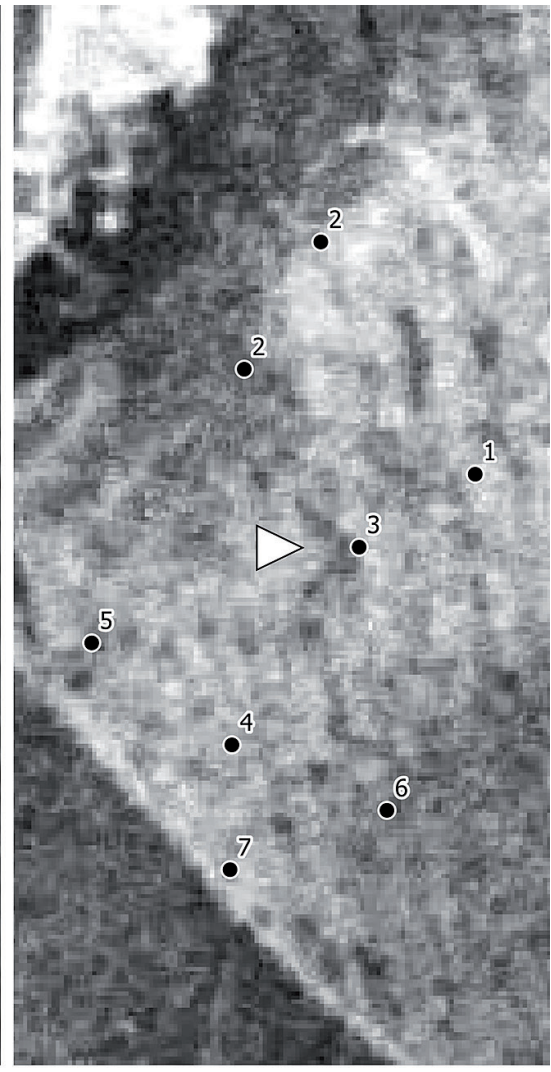

Vuelo Americano Serie B 1956

Fig. 5. Izquierda, Interpretación de la imagen ortorectificada de Del Olmo 1999. Centro: fotograma del vuelo interministerial con indicación de las zonas interpretadas sobre Del Olmo. Derecha. Vuelo USAF-Serie B con interpretación y triangulo apuntando a estructura de L invertida. Elaboración propia. / linterpretation of the corrected oblique photography from Del Olmo (Left). Image from "Interministerial flight" with indication of interpreted features (Center). USAF-B series flight with interpretation and arrow pointing to L-shape feature (Right). Image by authors.

${ }^{4}$ Coberturas consultadas a través de https://satellites.pro/mapa_de_Espana (Última consulta: 8 de enero de 2021). 


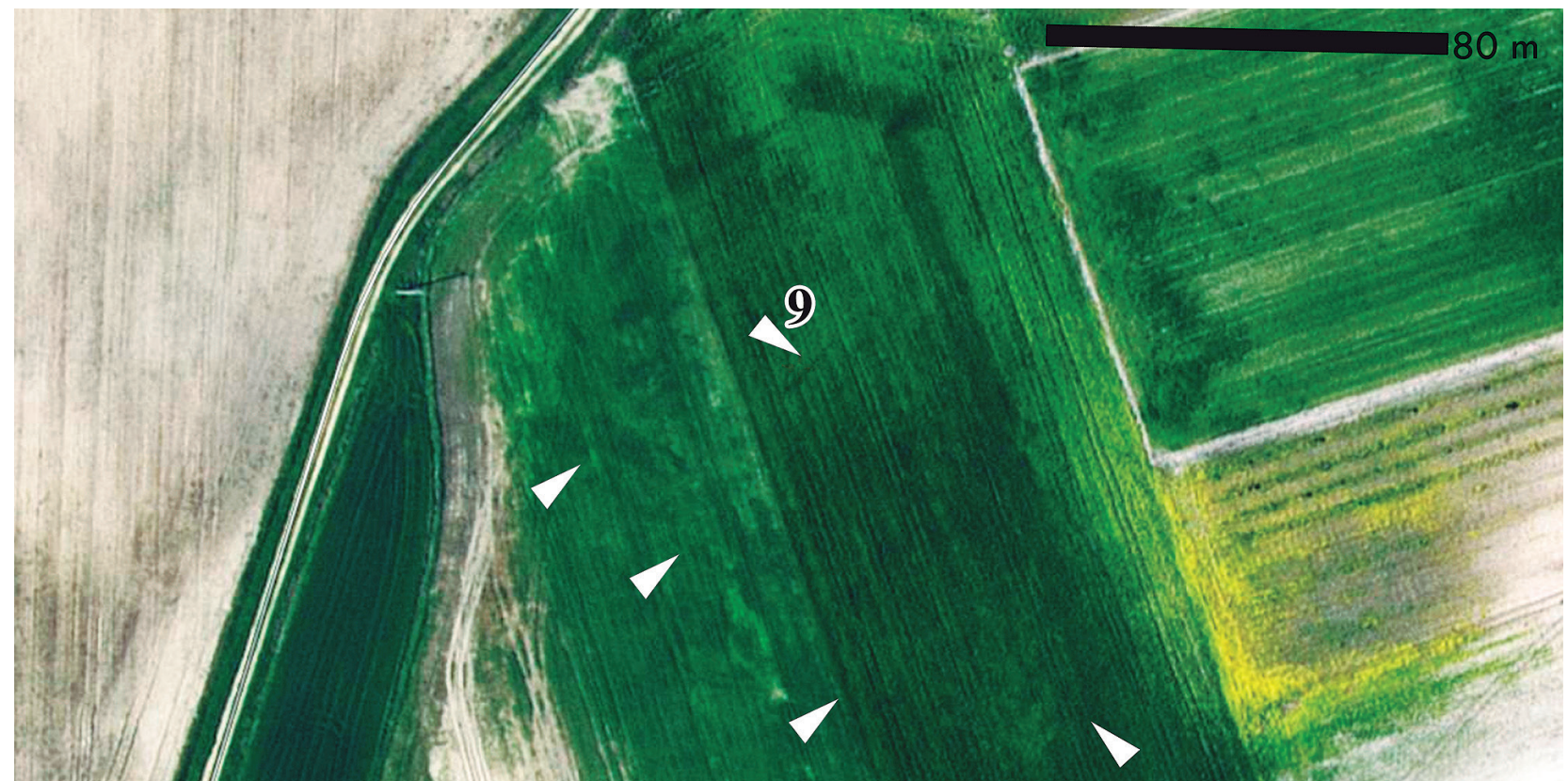

Fig. 6. Imagen de Apple maps con indicación de la estructura soterrada. Consultado en enero de 2021. Elaboración propia. / Apple maps image with indication of subsurface structures. Access to the image on January 2021. Image by authors.

Aunque la calidad de la imagen no es suficiente como para dibujar una planta, sí podemos intuir una distribución similar al reconocido en la fotografía de Del Olmo. Asimismo, documentamos una pequeña línea de color más oscuro, tal vez una depresión en el terreno o una estructura negativa (9).

\subsection{Análisis de los índices de vegetación y suelo}

De los índices calculados de forma exploratoria para este trabajo, ya mencionados en el anterior apartado, son: Ios índices SAVI (Huete, 1988) y GEMI (Pinty \& Verstraete, 1992) los que nos permiten reconocer algunos elementos de interés en el entorno de la pars urbana de la villa de Almenara de Adaja-Puras, aunque desgraciadamente no directamente relacionado con el edificio de la Laguna de El Monduengo. En este trabajo señalaremos únicamente aquellos elementos directamente relacionados con el complejo junto a este lavajo, dejando otras trazas en estudio para posteriores trabajos.

El resultado del análisis multiespectral de índices de vegetación y suelos no ha resultado positivo para la detección de las estructuras del complejo romano (Figura 7). Aquí hemos de señalar que, en el momento de la toma de la fotografía, la parte del yacimiento situada al oeste estaba inculta, aunque el terreno había sido alisado para la plantación de girasol, y la parcela situada al este albergaba un cultivo, posiblemente de yeros o pasto en un momento muy avanzado de su ciclo fenológico. Por lo tanto, no pudimos extraer ninguna diferencia relevante en el espectro electromagnético de esta zona, que es lo que en última instancia posibilita la interpretación de estructuras arqueológicas.
Por lo que respecta a los índices de suelo $(\mathrm{RI}, \mathrm{Cl}, \mathrm{BI}$ y $\mathrm{BI}$ 2) el resultado es muy homogéneo debido al estado del campo. No obstante, los índices BI y BI2 permitirían observar dos líneas paralelas coincidentes con la estructura 6. Esta zona se localiza en el lindero entre las dos fincas actuales, donde quizás el suelo esté más expuesto y permita apreciar estas diferencias mediante los índices correspondientes.

\subsection{Resultados de la prospección geofísica}

La prospección geofísica con georradar ha permitido sacar a la luz un edificio que, a grandes rasgos, coincide con la interpretación de la fotografía oblicua desarrollada a partir de la fotografía de Del Olmo. Además, como veremos más adelante, los 20 años transcurridos entre la imagen original de Del Olmo y la prospección realizada en 2020 han incidido en su paulatina destrucción.

Las estructuras del edificio romano son visibles a partir de $50 \mathrm{~cm}$ de profundidad y pueden observarse con claridad hasta los $120 \mathrm{~cm}$. Reconocemos un conjunto con una ligera orientación noroeste, que ocupa aproximadamente media hectárea; las medidas de los lados noroeste, suroeste y sureste son de 53,3 metros, 73,9 metros, y 45,9 metros respectivamente (Fig. 8). Tal y como sospechábamos al evaluar la imagen de Del Olmo, se aprecia un gran espacio a cielo abierto (A) bordeado claramente al suroeste y sureste por alas que muestran indicios de compartimentación interna; se trata respectivamente de las letras I y K. Al noreste la organización es más compleja, reconociéndose dos ambientes más amplios (B -de 13 por 14,2 metros- y C -de 6,9 por 8,5 metros-). Esta diferencia puede deberse 

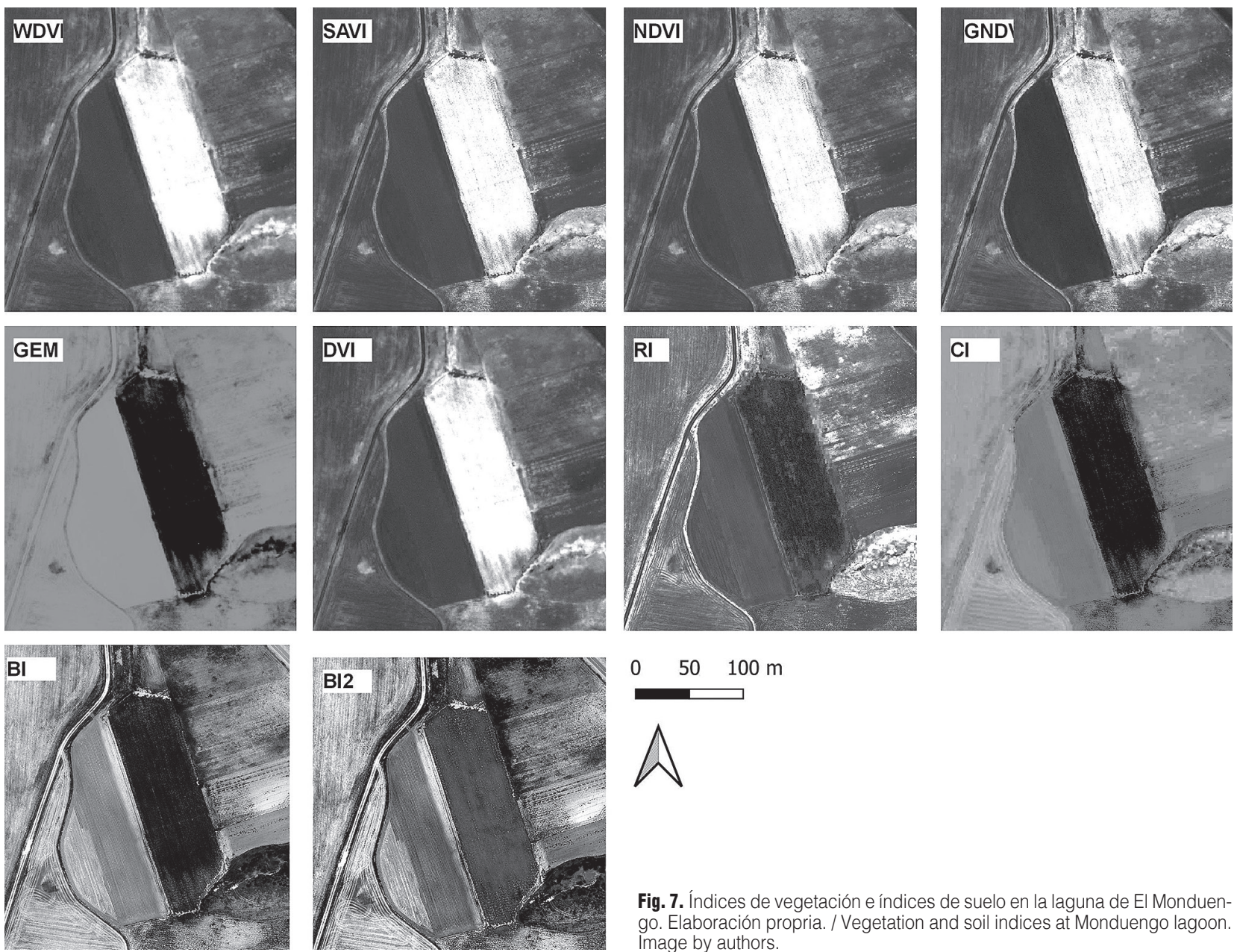

\section{$0 \quad 50 \quad 100 \mathrm{~m}$}

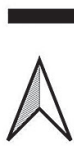

Fig. 7. Índices de vegetación e índices de suelo en la laguna de El Monduengo. Elaboración propria. / Vegetation and soil indices at Monduengo lagoon. Image by authors.

a la destrucción producida por la labor continua de los trabajos agrícolas.

Uno de los elementos más interesantes es la lectura estratigráfica de los cortes horizontales de los datos. Los cortes efectuados cada $20 \mathrm{~cm}$ de profundidad nos permiten detectar fases en el desarrollo del edificio.

Inmediatamente al este del bloque principal del edificio que hemos descrito, encontramos una serie de estancias- Dos de ellas se encuentran agrupadas (D y E) junto a otra estancia. Este grupo forma una nave rectangular anexa $(F)$ que ofrecen una alineación diferente. La aparición de estas evidencias en los cortes más superficiales y cuya orientación sí coincide con la de los edificios de la villa tardía, pudiera indicar que fueron coetáneas. Otro de los elementos detectados se ubica en el patio A, a una profundidad mayor (unos 60 $\mathrm{cm}$ ); se trata de una estructura rectangular (G) de 14,4 por 7,6 metros con 3 divisiones internas.

Además, creemos que es posible reconocer varias naves paralelas, quizás 3 con un ancho de 7,3 metros $(\mathrm{H}), 4,2$ metros (I) y 3,4 metros $(\mathrm{J})$ respectivamente desde el exterior (oeste) hacia el interior (este). 

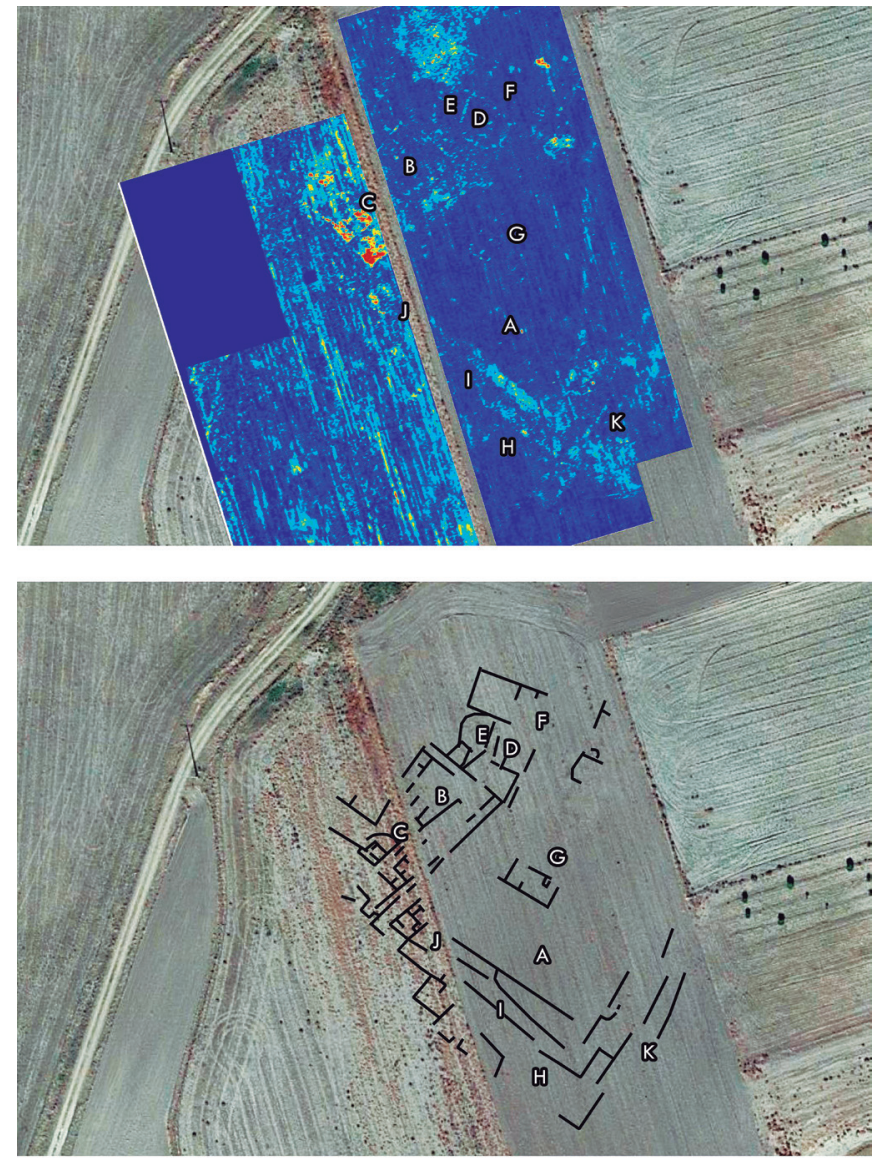

Fig. 8. Corte de profundidad a $60 \mathrm{~cm}$ con indicación de las estructuras referidas en el texto. Elaboración propia. / Slice view at $60 \mathrm{~cm}$ depth with indication of features described in the text. Image by authors.

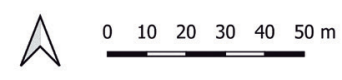

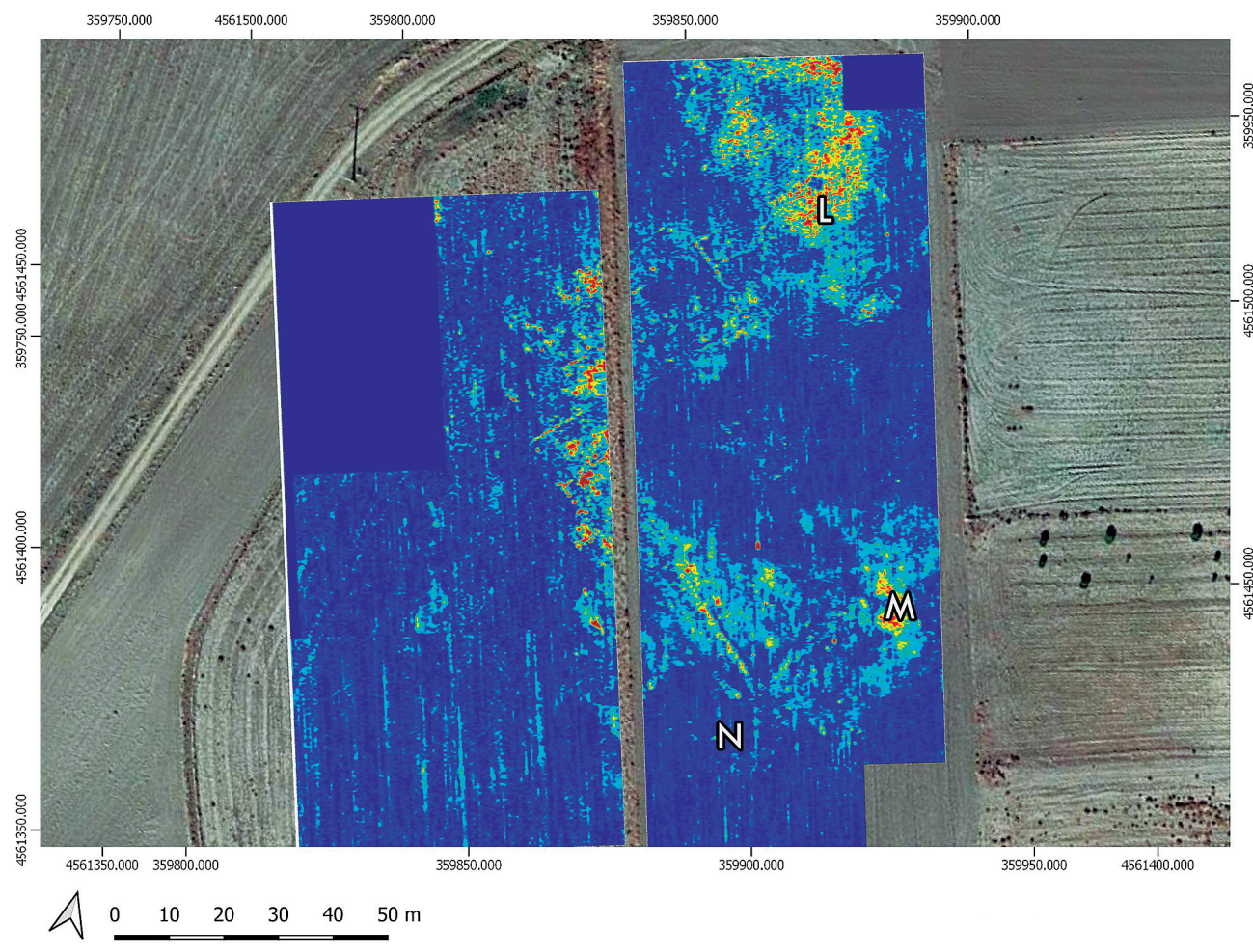

Fig. 9. Corte de profundidad a $80 \mathrm{~cm}$ con indicación de estructuras mencionadas en el texto. / Slice view at $80 \mathrm{~cm}$ with indication of features described in the text. 


\begin{tabular}{|c|c|c|c|c|}
\hline Método & ID & Definición & Medidas & Equivalencia \\
\hline \multirow{14}{*}{$\begin{array}{l}\frac{1}{1} \\
\frac{0}{0} \\
1 \\
\tilde{~} \\
\frac{0}{0} \\
\frac{0}{0} \\
\frac{0}{0} \\
0\end{array}$} & A & Patio central & $40 * 58 * 34$ & 1 \\
\hline & B & $\begin{array}{l}\text { Espacio } \\
\text { indeterminado }\end{array}$ & $13^{*} 14,2$ & 2 \\
\hline & C & $\begin{array}{l}\text { Espacio } \\
\text { indeterminado }\end{array}$ & $6,9 * 8,5$ & 2 \\
\hline & D & Estancia rectangular & $11,1^{*} 9,5$ & \\
\hline & E & Estancia rectangular & $6,9^{*} 10,3$ & \\
\hline & $\mathrm{F}$ & $\begin{array}{l}\text { Parte de edificio } \\
\text { rectangular }\end{array}$ & $10 * 20,6$ & \\
\hline & G & $\begin{array}{l}\text { Construcción en } \\
\text { patio central }\end{array}$ & $6,3^{*} 12,8$ & \\
\hline & $\mathrm{H}$ & Construcción tipo ala & $7,3^{*} 53,7^{*} 10,6$ & $3 / 6 ?$ \\
\hline & 1 & Construcción tipo ala & $4,2^{*} 56,4$ & $3 ?$ \\
\hline & J & Construcción tipo ala & $3,4 * 51$ & 3 \\
\hline & $\mathrm{K}$ & Construcción tipo ala & $8,6^{*} 30$ & \\
\hline & $\mathrm{L}$ & Derrumbe & & \\
\hline & M & Derrumbe & & \\
\hline & $\mathrm{N}$ & ¿Conducción? & 42,6 & \\
\hline \multirow{10}{*}{ 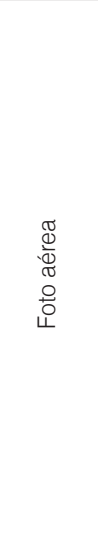 } & 1 & Patio central & $29 * 44.3$ & A \\
\hline & 2 & $\begin{array}{l}\text { Espacio } \\
\text { indeterminado }\end{array}$ & $14.7^{*} 11.2^{*} 14.2$ & B \\
\hline & $2 \mathrm{~A}$ & $\begin{array}{l}\text { Espacio } \\
\text { indeterminado }\end{array}$ & $18.9 * 21.8$ & C \\
\hline & 3 & Estancia & $\begin{array}{l}8.7^{*} 17.32 \\
\text { (incompleta) }\end{array}$ & $J / I$ \\
\hline & 4 & Patio central & $?$ & \\
\hline & 5 & Estancia & $13.4^{*} 14.9^{*} 13.5$ & $\mathrm{C} / \mathrm{J}$ \\
\hline & 6 & Estancias & $i$ & $\mathrm{H}$ \\
\hline & 7 & Estancia & $10^{*} 18.4^{\star} 7.1$ & no visible \\
\hline & 8 & $\begin{array}{l}\text { Estructura en } \\
\text { orma de L }\end{array}$ & $7.9 * 8.5$ & 3/ G? \\
\hline & 9 & Líneas paralelas & 10 metros & 3 \\
\hline
\end{tabular}

Tabla 2: Resumen de las estructuras localizadas con los métodos descritos, fotografía área y georradar. / Summary of detected features using aerial photography and GPR.

\section{DISCUSIÓN}

Las residencias y complejos productivos organizados en torno a grandes patios no son desconocidos en el mundo rural de época romana. Un buen ejemplo de ello se encuentra en este mismo sitio arqueológico de Almenara de Adaja-Puras, a unos 150 m de distancia, en el entorno del lavajo de El Arroyuelo. Junto a ese bodón, en la fase comprendida entre el siglo III y la primera mitad del IV, se levantaron varias alas rústicas delimitando patios. Con posterioridad, a mediados de esa cuarta centuria, se arrasaron las estructuras previas y se diseñó un nuevo proyecto compuesto, teniendo en cuenta los datos que actualmente disponemos, por una pars urbana y, anexas, dos largas naves compartimentadas. Estos tres bloques de construcciones se dispusieron en torno a un gran espacio abierto, cuadrado de aproximadamente 70 metros de lado, respectivamente al este, norte y sur (García-Merino \& Sánchez-Simón, 2015, pp 69-72, 106).
La aplicación de metodologías de prospección similares a las seguidas en este yacimiento ha proporcionado importantes hallazgos en otras villas hispanas, y entre ellas en tres ejemplos del valle del Duero, lo que nos ayuda a mejorar el marco comparativo con este caso vallisoletano. Todos muestran plantas extensas organizadas en torno a grandes patios, seguramente una combinación de la función señorial de representación y productiva inherente a estas grandes quintas tal y como se comprueba en el caso de Almenara de Adaja-Puras. Una de ellas es la villa de Los Villares en Fresno-Alhándiga (Pérez de Dios \& De Soto-García, 2017), fechada a partir del siglo IV d.C., donde la concentración de materiales relacionados con el sitio arqueológico llega a ocupar 20 hectáreas de terreno, y donde la prospección geofísica ha permitido documentar también un gran complejo vilicario cuyos resultados están aún en elaboración (de Soto comunicación personal). Un ejemplo de reciente estudio es el yacimiento de Vegas Negras en Huérmeces, un sitio ya conocido a partir de las prospecciones de la carta arqueológica de Burgos. La planta de esta villa no fue conocida hasta recientemente, momento en el que pudo apreciarse con gran detalle la planimetría en la fotografía aérea y también en la prospección geofísica (Carmona Ballesteros et al. 2021). En este caso, una prospección artefactual orientada a caracterizar la funcionalidad de los espacios clasificando las nubes de punto obtenidas con GPS de mano (García Sánchez, 2013) quiere comprender mejor la relación entre el material arqueológico en superficie y la planta observada. Finalmente, la villa de Manciles, en Burgos, reviste igual interés en comparación con la de Vegas Negras, por su cercanía a un cauce fluvial. Este yacimiento, también conocido por su dispersión de materiales en una amplia zona, presenta igualmente un área a cielo abierto de grandes dimensiones rodeada por naves compuesta por estancias cuadradas y una zona principal, seguramente de residencia, organizado en torno a un patio o peristilo. Este complejo ocupa un pequeño valle ubicado en el centro del páramo burgalés, una zona con muy bajo rendimiento agrícola salvo en las zonas interiores surcadas por valles, además se sitúa no lejos de las ciudades de Segisamo y Deobrigula, núcleos de relativa importancia como núcleo vertebrador para el comercio de excedentes a través de la vía Ab Asturica Burdigalam (Abásolo, 1998; García Sánchez, 2012; Moreno Gallo, 2001; Pradales Ciprés \& Sagredo, 1993).

Otros ejemplos conocidos en Castilla y León por el trabajo de Del Olmo son los de las villas de San Pedro (Fuentecén) e Hinojar del Rey, en la provincia de Burgos; las de La Palatina (El Guijar) y La Revilla (Sequera del Fresno) en la de Segovia; y las vallisoletanas de Arco Galiano (Torrelobatón), Las Quintanas (Torrelobatón), El Prado y Valdiliña (ambas en Canillas de Esgueva), La Serna (Castroverde de Cerrato), Santa Olalla (Villardefrades), Las Quintanas (Montealegre) y Fuente de la Vega (Tudela de Duero) (Del Olmo, 2017). En todas ellas se aprecian trazas que permiten recono- 
cer proyectos constructivos basados en grandes patios entorno a los cuales se organizan diferentes bloques constructivos. Algunos responden la planimetría de alas alargadas compartimentadas que suelen relacionarse con la zona rústica; en otros casos la complejidad de las estructuras parece hacer referencia tanto a partes urbanas como a otras funcionalidades, probablemente agropecuarias.

Hay en Lusitania otro ejemplo recientemente investigado por uno de nosotros (JGS) y que ofrece la misma pauta. Es la villa de Horta da Torre (Cabeço de Vide, Portugal) (Carneiro, 2017; Carneiro et al., 2019), en el que se ha combinado la prospección intensiva del entorno con la geofísica sobre una gran extensión de terreno más allá de los límites de la excavación liderada por A. Carneiro. Esta prospección con georradar sacó a la luz una estructura monumental organizada en torno a dos grandes patios rodeados por estancias cuadradas y algunas naves con posibles fines de almacenamiento. Nuevamente, la cronología de la construcción de Horta de Torre es similar a la de los casos señalados anteriormente, aunque por el momento se desconoce dónde pudo localizarse una posible construcción altoimperial documentada por los materiales en superficie. Otras prospecciones geofísicas combinando la inducción magnética y el georradar han permitido definir una nueva área de ocupación al norte del edificio principal de la villa.

Finalmente señalaremos la importancia de considerar el análisis de las villas romanas de Hispania desde una perspectiva global donde los estudios clásicos y las nuevas tecnologías se den la mano. El elemento interesante es que, gracias a la aplicación de nuevos métodos no centrados exclusivamente en la excavación de las salas de recepción y sus ricos mosaicos de las partes urbanas, podemos obtener información valiosa acerca de la configuración arquitectónica y organización productiva de estos complejos a una escala mucho mayor; en otras palabras, estamos conociendo la entidad real de muchas de las villas romanas del valle del Duero.

\section{CONCLUSIONES}

La integración de varias técnicas geoespaciales donde se combinan datos de diferentes fuentes, y de periodos diversos (desde 1956 hasta 2020) ha permitido arrojar suficientes indicios como para corroborar la existencia de un importante edificio vilicario en las inmediaciones del lavajo de El Monduengo, correspondiente a la fase anterior a la de la construcción del palacio bajoimperial (García-Merino \& Sánchez-Simón, 2015, pp. 69-72). La estructura en forma de gran patio central abierto, circundado por estancias de posible función productiva y por un bloque destinado probablemente a la residencia, repite un modelo ampliamente conocido que tiene su exponente más cercano en la propia pars urbana de la villa de Almenara de Ada-
ja-Puras (García-Merino \& Sánchez-Simón, 2015, pp. 69-73). Otros yacimientos, que también son objeto de investigaciones más recientes como Horta da Torre, Vegas Negras y Los Villares, ofrecen datos similares que han sido registrados de forma no invasiva sobre el total de los restos preservados bajo la superficie.

Esta aproximación, realizada a través de métodos de prospección geofísica, permite comprender de manera extensiva tanto el núcleo residencial de estos yacimientos como su área inmediata. La información generada, lejos de ser un mero indicador para posibles intervenciones arqueológicas se convierte en una información relevante para comprender la organización del espacio y la evolución de la villa a lo largo del tiempo, constituye pues una información suficientemente relevante en si misma para contribuir a la comprensión de la colonización y explotación del medio rural en la Hispania romana. Y más allá de eso, hoy en día la prospección geofísica o la teledetección es un componente imprescindible para la aplicación de otros métodos como la prospección artefactual o la excavación.

\section{AGRADECIMIENTOS}

Agradecemos a la Junta de Castilla y León la financiación de los trabajos de prospección ( $N^{\circ}$ de expediente B2020/004771) y los permisos de trabajo en la zona ( $\mathrm{N}^{\circ}$ de expediente 20/124-VA) y a la dirección y personal del MVR (Museo de las Villas Romanas de Almenara-Puras) por su colaboración y hospitalidad durante las campañas de trabajo. Jesús García Sánchez es investigador contratado a cargo del Programa de Atracción de Talento TA18060 de la Junta de Extremadura y Margarita Sánchez Simón es parte del grupo HESPERIA. GIR sobre la Península Ibérica en la Antigüedad de la Universidad de Salamanca.

Asimismo, queremos agradecer a Eduardo Arancón Torrecilla y Francisco J. González de la Fuente su colaboración en las tareas de prospección geofísica, y a José Manuel Costa-García por la revisión del texto original.

\section{BIBLIOGRAFÍA}

Abásolo, J. A., 1998. La ciudad de Segisamo. In: Rodríguez Colmenero, A. (Ed.), Los orígenes de la ciudad en el Noroeste hispánico. Actas del Congreso Internacional, 585- 598.

Ariño, E., Gurt Esparraguera, J. L., \& Palet Martínez, J, 2004. El pasado presente. Arqueología de los paisajes en la Hispania romana. Universidad de Salamanca: Salamanca.

Bennett, R., Welham, K., Hill, R. A., Ford, A. L. J, 2012. The Application of Vegetation Indices for the Prospection of Archaeological Features in Grass-dominated Environments. Archaeological Prospection 19(3), 209-218. https://doi. org/10.1002/arp.1429

Brassous, L., Didierjean, F., Guillot, B., Ruiz Velez, I., 2015. Monuments vus du ciel. Les apports de la photographie aérienne à l'urbanisme de Tritium Autrigonum (Monasterio de Rodilla, 
Burgos). Monumental ! La monumentalisation des villes de l'Aquitaine et de l'Hispanie septentrionale durant le Haut-Empire, Sep 2015, Villeneuve-sur-Lot, France.

Campana, S., Piro, S, Eds., 2008. Seeing the Unseen. Geophysics and Landscape Archaeology Taylor \& Francis: New York.

Carneiro, A., 2017. O final das villae na Lusitania Romana. O exemplo da Horta da Torre (Fronteira). Urbs Regia 2, 56-59.

Carneiro, A., García Sánchez, J., Stek, T., Kalkers, R, 2019. Primeiros Resultados do Fronteira Landscape Project: A Arqueologia da paisagem romana no Alto Alentejo. Al-madan Online 22(33), 46-54.

Carmona Ballestero, E., Cortés Bárcena C., García Rojo, A., Vega Maeso y C, Conde Moreno, J F., 2021. Vegas Negras (Huérmeces, Burgos): análisis de evidencias a partir de las imágenes aéreas y la prospección de superficie. In: Martínez, R., Nogales, T. y Rodà I. (coords.), Actas del Congreso "Las Villas Romanas Bajoimperiales de Hispania" Palencia, 15, 16 y 17 de noviembre, 163-172. Diputación de Palencia: Palencia.

Catapano, I., Gennarelli, G., Ludeno, G., Soldovieri, F.,Persico, R, 2019. Ground-Penetrating Radar: Operation Principle and Data Processing. In: Wiley Encyclopedia of Electrical and Electronics Engineering, 1-23. https://doi.org/10.1002/047134608X. W8383

Conyers, L. B., 2004. Ground-Penetrating Radar for Archaeology. Altamira Press, Walnut Creek.

Del Olmo, J., 2017. Arqueología aérea en Castilla y León. Alfredo Castro Castro, Valladolid.

Didierjean, F., 2015. Trazas de actividad militar: Metodología crítica de la investigación. In: Camino Mayor, J., Peralta Labrador, E., Torres Martínez, J.F. (Eds.), Las Guerras Astur-Cántabras. KRK ediciones, Oviedo, 293-304.

Donati, J. C., Sarris, A., 2016. Evidence for Two Planned Greek Settlements in the Peloponnese from Satellite Remote Sensing. American Journal of Archaeology 120(3), 361-398. https://doi. org/10.3764/aja.120.3.0361

García Entero, V., 2007. La investigación de las villae romanas de la Meseta. In: Revilla, V., González, J.R. Prevosti, M. (Eds.), Les villes romanes a la Tarraconense. Implantació, evolució i transformació. Estat actual de la Investigació del món rural en època romana (Museu d'Arqueologia de Catalunya, 27-47.

García García, M., 2013. Las Pozas (Casaseca de las Chanas, Zamora): Dos nuevos recintos de fosos calcolíticos en el Valle del Duero. Trabajos de Prehistoria 70(1), 175-184. https://doi. org/10.3989/tp.2013.12108

García-Merino, C., Sánchez-Simón, M., 2015. La villa romana de Almenara de Adaja-Puras a través de los archivos del tiempo. Diputación de Valladolid: Valladolid.

García Sánchez, J., 2012. Arqueología y paisaje en el noroeste de Burgos: La transición de la Segunda Edad de Hierro a época romana a través del registro material [Universidad de Cantabria]. http://www.tdx.cat/handle/10803/80486

García Sánchez, J., 2013. Metodologías de prospección a escala regional y artefactual en la comarca. La prospección del Ager Segisamonensis; comarca Odra-Pisuerga (Burgos. Complutum 24(1), 9-28. https://doi.org/10.5209/rev_CMPL.2013. v24.n1.42322

Garcia Sanchez, J., Costa García, J. M., 2020. Del oppidum indígena a la ciudad romana. Evolución del paisaje de Segisamo (Sasamón, Burgos, España) a través de la fotografía aérea. Da- tos de la prospección aérea de 2019. Lucentum 39, 131-148.

Goodman, D., Piro, S., 2013. GPR Remote sensing in Archaeology. Springer: New York.

Huete, A. R., 1988. A soil-adjusted vegetation index (SAVI. Remote Sensing of Environment, 25(3), 295-309. https://doi. org/10.1016/0034-4257(88)90106-X

Liz Guiral, J., Célis Sánchez, J., 2007. Topografía antigua de la ciudad de Lancia (Villasabariego, León, España. Zephyrus: Revista de prehistoria y arqueología, 60, 241-263.

Manataki, M., Sarris, A., Donati, J., Cuenca-García, C., 2015. GPR: Theory and Practice in Archaeological Prospection. In: A. Sarris (Ed.), Best Practices of Geolnformatic Technologies for the Mapping of Archaeolandscapes. ArchaeoPress, London, 13-24 https://doi.org/10.13140/RG.2.1.3256.9363

Menéndez Blanco, A. M., García Sánchez, J., Costa-García, J. M., Fonte, J., González-Álvarez, D., Vicente García, V., 2020. Following the Roman Army between the Southern Foothills of the Cantabrian Mountains and the Northern Plains of Castile and León (North of Spain): Archaeological Applications of Remote Sensing and Geospatial Tools. Geosciences 10(12), 485. https://doi.org/10.3390/geosciences10120485

Moreno Gallo, I, 2001. Descripción de la vía romana de Italia a Hispania en las provincias de Burgos y Palencia. Diputación Provincial de Burgos, Burgos.

Mayoral Herrera, V, 2016. La revalorización de zonas arqueológicas mediante el empleo de técnicas no destructivas: Reunión científica, Mérida (Badajoz, España), 12-13 de junio de 2014. Consejo Superior de Investigaciones Científicas, Madrid.

Opitz, R., Cowley, D. C, 2013. Interpreting Archaeological Topography: 3D Data, Visualisation and Observation. Oxbow, Oxford.

Palmer, R., \& Cowley, D, 2010. Interpreting aerial images - developing best practice. In: F. Maurizio, S. Campana, \& Liuzza (Eds.), Space, Time, Place: Third International Conference on Remote Sensing in Archaeology, 17th-21st August 2009, Tiruchirappalli, Tamil Nadu, India. ArcheoPress.

Pérez de Dios, V., De Soto-García, M. de los R, 2017. Los Villares (Fresno Alhándiga, Salamanca): Un complejo termal junto a la Vía de la Plata. Munibe Antropologia-Arkeologia 68, 237249. https://doi.org/10.21630/maa.2017.68.08

Pinty, B., Verstraete, M, 1992. GEMI: A non-linear index to monitor global vegetation from satellites. Vegetation 101, 15-20. https://doi.org/10.1007/BF00031911

Pradales Ciprés, D., Sagredo, D, 1993. Los orígenes del poblamiento castreño en Deobrigula. Hispania antiqua 17, 119-142.

Sacristán de Lama, J. D, 2011. El urbanismo vacceo. Complutum 22(2), 185-222.

Salgado Carmona, J. Á., Quirós, E., Mayoral, V., Charro, C, 2020. Assessing the potential of multispectral and thermal UAV imagery from archaeological sites. A case study from the Iron Age hillfort of Villasviejas del Tamuja (Cáceres, Spain. Journal of Archaeological Science: Reports 31, 102312. https://doi.org/10.1016/j.jasrep.2020.102312

Sarris, A., \& Cantoro, G, 2015. Geophysical prospection in the territory of the Roman town of Aesernia, central southern Italy. Archaeologia Polona 53, 347-350.

Sarris, A., Kalayci, T., Papadopoulos, N., Argyriou, N., Donati, J., Kakoulaki, G., Manataki, M., Papadakis, M., Nikas, N., Scotton, P., Kissas, K, 2020. Geophysical explorations of the clas- 
sical coastal settlement of Lechaion, Peloponnese (Greece. In: Dabas, M., Campana, S., Sarris, A. (Eds.), Mapping the Past From sampling sites and landscapes to exploring the 'archaeological continuum'. ArchaeoPress: London, 43-52.

Seren, S., Eder-Hinterleitner, A., Neubauer, W., Löcker, K., Melichar, P, 2007. Extended comparison of different GPR systems and antenna configurations at the Roman site of Carnuntum. Near Surface Geophysics 5(6), 389-394. https://doi. org/10.3997/1873-0604.2007021

Uribe Agudo, P., Angás Pajas, J., Pérez-Cabello, F., Redón, J. V., Ezquerra Lebrón, B, 2018. The Potential of Drones and Sensors to Enhance Detection of Archaeological Cropmarks: A Comparative Study Between Multi-Spectral and Thermal Imagery. Drones 2(3), 29. https://doi.org/10.3390/drones2030029

Verdonck, L., Launaro, A., Vermeulen, F., Millett, M, 2020. Ground-penetrating radar survey at Falerii Novi: A new approach to the study of Roman cities. Antiquity 94(375), 705723. https://doi.org/10.15184/aqy.2020.82

Verdonck, L., Taelman, D., Corsi, C., Vermeulen, F, 2012. Ground Penetrating Radar at Ammaia. In: Corsi, $\mathrm{CH}$., VermeuIen, F. (eds.), AMMAIA I: THE SURVEY A Romano-Lusitanian Townscape Revealed, 69-81. Academia Press, Ghent.

Verhoeven, G, 2012a. Near-Infrared Aerial Crop Mark Archaeology: From its Historical Use to Current Digital Implementations. Journal of Archaeological Method and Theory 19(1), 132-160. https://doi.org/10.1007/s10816-011-9104-5

Verhoeven, G, 2012b. Rethinking the Spectrum-The Digital (R)Evolution in Archaeological Aerial Reconnaissance. In: Johnson, P., Millet, M. (Eds.), Archaeological survey and the city. Oxbow Book, Oxford, 45-67. https://doi.org/10.2307/j.ctvh1dwwz.7

Vermeulen, F, 2013. Roman Urban Survey: The mapping and monitoring of complex settlement sites with active aerial photography. In: Corsi, C., Vermeulen, F., Slapsak, B. (Eds.) Good practice in archaeological diagnostics: Non-invasive survey of complex archaeological sites. Springer: New York 69-85. 